\title{
Pheochromocytoma and Paraganglioma pT2 TNM Finding v8
}

National Cancer Institute

\section{Source}

National Cancer Institute. Pheochromocytoma and Paraganglioma pT2 TNM Finding v8. NCI Thesaurus. Code C141122.

Pheochromocytoma measuring $5 \mathrm{~cm}$ or more in greatest dimension or paragang liomasympathetic of any size, with no extra-adrenal invasion. (from AJCC 8th Ed.) 